\title{
In Vitro and in Vivo Antibacterial Activities of Cyanidinum Chloride-loaded Liposomes against a Resistant Strain of Pseudomonas aeruginosa
}

Authors

Affiliations
Amir Gharib ${ }^{1}$, Zohreh Faezizadeh ${ }^{1}$, Seyed Ali Reza Mesbah-Namin ${ }^{2}$

${ }^{1}$ Department of Laboratory Sciences, Borujerd Branch, Islamic Azad University, Borujerd, Iran

${ }^{2}$ Department of Clinical Biochemistry, Faculty of Medical Sciences, Tarbiat Modares University, Tehran, Iran
Key words

- cyanidinum chloride

- liposome

- Pseudomonas aeruginosa

- killing rates

- in vitro

- in vivo received June 12, 2012

revised October 12, 2012

accepted October 21, 2012

Bibliography

DOI http://dx.doi.org/

10.1055/s-0032-1327952

Published online November 30 ,

2012

Planta Med 2013; 79: 15-19

(c) Georg Thieme Verlag KG

Stuttgart · New York.

ISSN 0032-0943

\section{Correspondence}

Dr. Amir Gharib

Department of Laboratory

Sciences

Faculty of Medical Sciences

Borujerd Branch, Islamic Azad

University

Modares Street 1

Borujerd 14515-775

Iran

Phone: + 9866235002012

Fax: + 986624453013

amirgharib@gmail.com

\section{Abstract}

$\nabla$

Pseudomonas aeruginosa remains a common cause of wound infections. Different studies have shown that the entrapment of plant-derived materials in liposomes could increase their antibacterial activity against Pseudomonas aeruginosa. The aim of this study was to prepare cyanidinum chloride-loaded liposomes and evaluate their in vitro and in vivo efficacy against a resistant strain of Pseudomonas aeruginosa ATCC 15692. Cyanidinum chloride-loaded liposomes were prepared by extrusion method. The minimum inhibitory concentrations of cyanidinum chloride in the free and liposomal forms against Pseudomonas aeruginosa ATCC 15692 were determined in vitro by broth dilution method. The in vitro killing rates for free and liposomal cyanidinum chloride were

\section{Introduction}

$\nabla$

Pseudomonas aeruginosa is an opportunistic pathogen that causes serious wound infections [1]. Since $P$. aeruginosa can quickly colonize and infect wound sites and rapidly disseminate from wounds into the bloodstream, the clinical outcome in these patients can lead to sepsis, which is often fatal [2]. One of the major problems associated with $P$. aeruginosa infection is resistance to most conventional antibiotics [1]. Therefore, there is a compelling need to develop novel agents, strategies, and methods to overcome this resistance [3].

Cyanidinum ion ( $\bullet$ Fig. 1 ), a hydrolysis product from cyanidin salts and a flavonoid occurring in many red berries, possesses a range of biological and medicinal properties, including antioxidant, anticancer, antiobesity, and antiviral activities [4, 5]. Other physiological functions of cyanidinum ion include anti-inflammatory activity and reduction in memory impairment effects [6,7]. It has analyzed. Ultimately, the in vivo therapeutic efficacy of the prepared liposomes in mice skin infected by ATCC 15692 was investigated. The minimum inhibitory concentrations of the free and liposomal forms of cyanidinum chloride against ATCC 15692 were $1.5 \times 10^{-3}$ and $7.7 \times 10^{-4} \mathrm{M}$, respectively. In vivo treatment with the free and cyanidinum chloride-loaded liposomes resulted in almost 40 and $100 \%$ survival rates, respectively. Our results showed that cyanidinum chlorideloaded liposomes would be a good choice for the treatment of wound infection caused by Pseudomonas aeruginosa because of their high effectiveness.

Supporting information available online at http://www.thieme-connect.de/ejournals/toc/ plantamedica

been shown that plant extracts that contain a wide range of polyphenolic compounds such as cyanidinum ion have antimicrobial activity against drug-resistant bacteria $[8,9]$. Cyanidinum ion has a major antibacterial and antifungal activity effect on Bacillus subtilis and yeast, respectively [10]. Also, this compound has antituberculosis activity [11].

Liposomes are spherical and colloidal vesicles that range from a few nanometers to several micrometers in diameter $[12,13]$. These carriers are composed of natural phospholipids and other lipids, such as cholesterol, and can be used as a vehicle for the administration of nutrients and pharmaceutical drugs [14-16].

Previous studies showed that the encapsulation of plant-derived materials into liposomes markedly alter their pharmacokinetics, increasing their half-lives and effectiveness [17,18]. While some of these compounds, such as usnic acid, have relative antibacterial effectiveness in the liposomal form, others, such as oleic acid, have been 


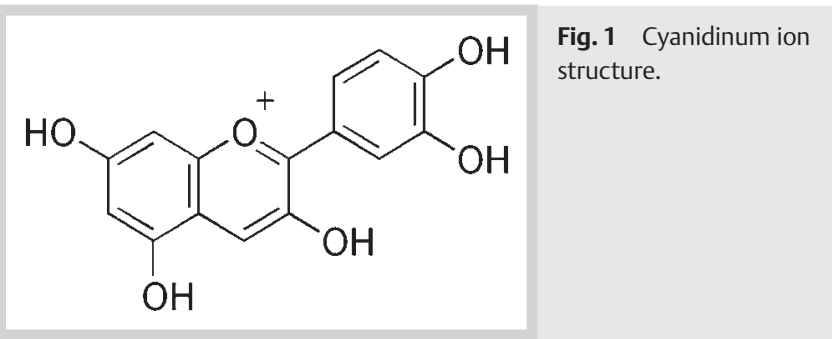

more effective in this formulation $[19,20]$. The anti-P. aeruginosa effectiveness of cyanidinum chloride-loaded liposomes has not yet been studied. The primary aim of this study was to prepare cyanidinum chloride-loaded liposomes and evaluate their in vitro antibacterial activity against the resistant strain of $P$. aeruginosa ATCC 15692. A secondary aim was to investigate the therapeutic efficacy of prepared liposomes using a mouse model of skin wounds infected with this bacterium.

\section{Materials and Methods}

$\nabla$

\section{Chemicals}

Cyanidinum chloride (purity $\geq 95 \%$ ), cholesterol, egg lecithin, and amikacin hydrate (an aminoglycoside antibiotic, as the positive control, purity $\geq 78 \%$ ) were purchased from the Sigma Chemical Company. Chloroform, HPLC grade methanol, and Mueller-Hinton broth were purchased from Merck.

\section{Animals}

Fifty male BALB/c mice (18-20 g) were obtained from the National Institute of Pasture, Iran. The mice were handled according to the national guidelines for laboratory animals, received food and water ad libitum and were housed in separate and pathogen-free cages [21]. Animal care and protocols were performed and approved by the Institutional Animals Ethics Committee of Tarbiat Modares University (Number: 145, Tehran, Iran, 3/3/2011).

\section{Microorganism}

P. aeruginosa ATCC 15692 was purchased from the American Type Culture Collection. This strain was inoculated onto blood agar plates and then incubated for $24 \mathrm{~h}$ at $37^{\circ} \mathrm{C}$ and used for experiments.

\section{Preparation of liposomes}

The cyanidinum chloride-loaded liposomes were prepared by the extrusion method, as described previously [17]. Briefly, the egg lecithin and cholesterol in the molar ratio of $4: 1$ were dissolved in chloroform and dried to a lipid film with a rotary evaporator (Brinkman) under vacuum and $\mathrm{N}_{2}$ flow at $30^{\circ} \mathrm{C}$. The dried lipids were dispersed by agitation in $6 \mathrm{~mL}$ of an aqueous solution of cyanidinum chloride ( $150 \mathrm{mg} / \mathrm{mL}$ in PBS, $\mathrm{pH} 7.4)$ and sonicated at $4^{\circ} \mathrm{C}$ in ultrasonic bath (Braun-sonic 2000). Finally, cyanidinum chloride-loaded liposomes were obtained by extruding the respective suspension through a polycarbonate membrane with $100 \mathrm{~nm}$-sized pores 12 times, and separating the excess free drug and larger lipid aggregation by ultracentrifugation $(100000 \mathrm{~g}$, $30 \mathrm{~min}$ ). The control liposomes were prepared similarly, but PBS ( $\mathrm{pH}$ 7.4) was used instead of the cyanidinum chloride solution.

\section{Determination of encapsulation efficacy}

The content of the cyanidinum chloride in the liposomes was determined by HPLC as previously described [22], and the percentage of cyanidin loading was then calculated as: amount of cyanidinum chloride in liposome $\times$ total volume tested $\times 100 /$ total sample volume $\times$ initial amount of cyanidinum chloride. This experiment was done in triplicate.

Particle size, zeta-potential, size distribution, and polydispersity index determination

The mean particle size, zeta-potential, size distribution, and polydispersity index of the liposomes were evaluated using a Malvern zetasizer (Malvern instrument) apparatus, as reported previously $[23,24]$. Each experiment was done in triplicate.

\section{Antimicrobial susceptibility testing}

The minimum inhibitory concentrations (MICs) of the free and cyanidinum chloride-loaded liposomes and amikacin for P. aeruginosa ATCC 15692 were determined by the broth dilution technique as recommended by CLSI (formerly NCCLS) [25]. A bacterial suspension of $\sim 5 \times 10^{5}$ cells $/ \mathrm{mL}$ was diluted in the Mueller-Hinton broth and dispensed $(100 \mu \mathrm{L})$ into a microtiter tray containing serial twofold dilutions of cyanidinum chloride. The tray was then incubated for $24 \mathrm{~h}$ at $37^{\circ} \mathrm{C}$. The MICs were recorded as the lowest concentrations of cyanidinum chloride in the free and liposomal forms that prevented visible bacterial growth and were expressed in $\mu \mathrm{g} / \mathrm{mL}$. All experiments were done in triplicate.

\section{Time-kill studies}

Time-kill studies were performed in triplicate in $10 \mathrm{~mL}$ tubes containing $2 \mathrm{~mL}$ of Mueller-Hinton broth as previously described [26]. Briefly, $100 \mu \mathrm{L}$ of the bacterial suspension were resuspended in $10 \mathrm{~mL}$ of the Mueller-Hinton broth, incubated overnight at $37^{\circ} \mathrm{C}$ and adjusted to a McFarland standard of 0.5 . Then, $100 \mu \mathrm{L}$ of this standardized inoculum were added to separate culture tubes containing $1 \mathrm{~mL}$ of Mueller-Hinton broth with $1 \mathrm{~mL}$ cyanidinum chloride solutions in the free and liposomal forms at 1,2 , and 4 times the MIC and incubated at $37^{\circ} \mathrm{C}$. Subsequently, colony counts were performed at $0,2,4,6$, and $24 \mathrm{~h}$, and the results were expressed as log colony forming unit per milliliter (CFU/mL). All experiments were performed in triplicate.

\section{Animal studies}

The in vivo therapeutic efficacy of cyanidinum chloride-loaded liposomes in a mouse skin suture-wound model was tested according to a described method [27], with some modifications. Briefly, sterile silk sutures were cut and threaded onto sterile surgical needles and soaked for $45 \mathrm{~min}$ in undiluted broth cultures of the P. aeruginosa ATCC 15692 that had been incubated at $35^{\circ} \mathrm{C}$ for $8 \mathrm{~h}$. The mice were anesthetized with a ketamine-xylazine mixture $(50 \mathrm{mg} / \mathrm{kg}$ each, given intramuscularly). Subsequently, the fur on the back and flanks was clipped, and the skin was swabbed with $70 \%$ ethanol. A 1-cm length of inoculated suture was inserted under the skin of the mid-back and secured by knotting the other side of the suture. Then the infected mice were divided into 5 groups. Prior to the treatment starting, the free and liposomal forms of cyanidinum chloride, empty liposomes, amikacin, and physiological saline solutions were prepared. Subsequently, the gel forms of these treatments were prepared according to a previously described method [28]. Then, all groups were treated topically as follows: group 1 received cyanidinum chlorideloaded liposomes gel (contained $250 \mathrm{mg}$ cyanidinum chloride/ 


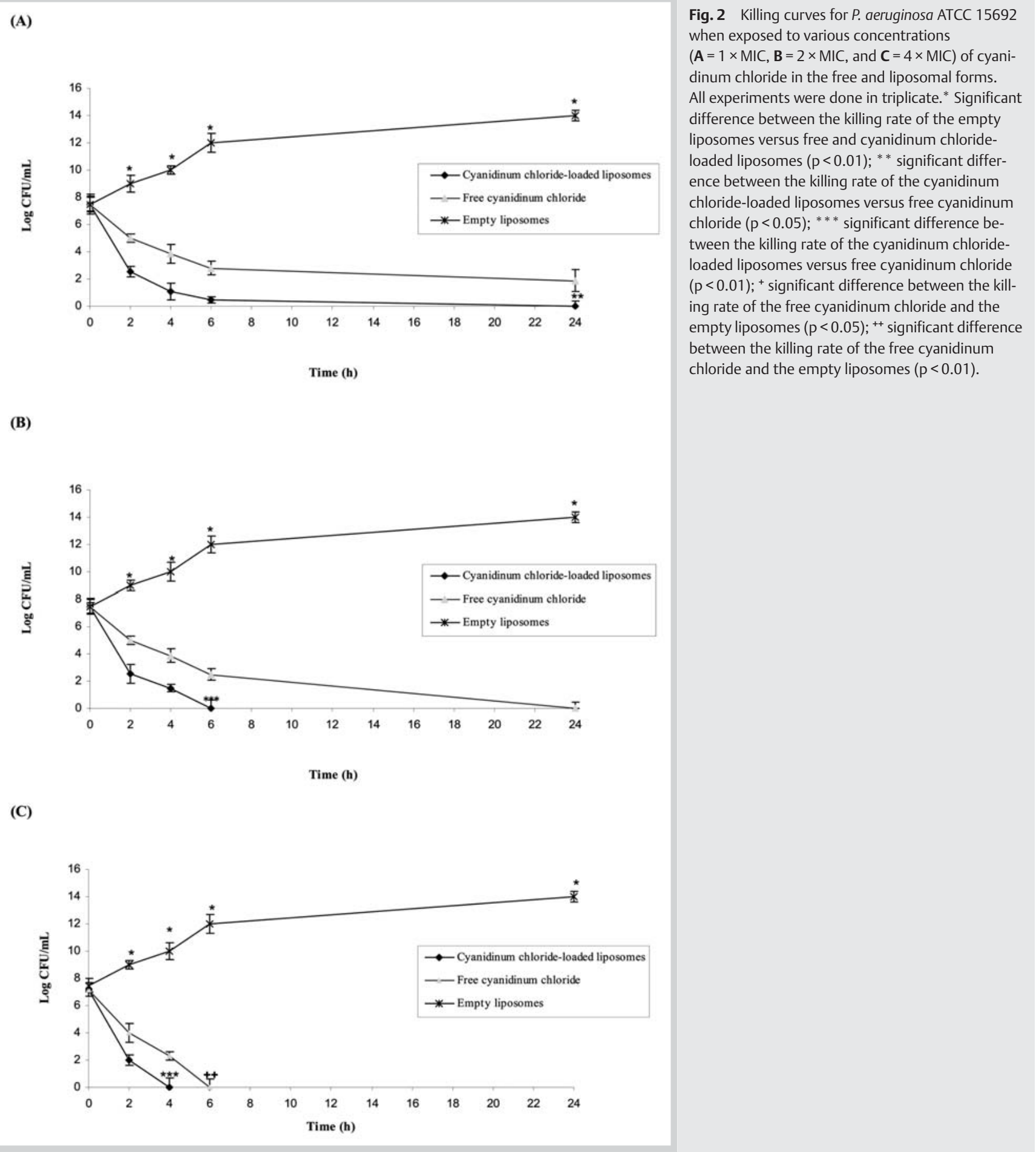

$\mathrm{kg} / 24 \mathrm{~h}$ ); group 2 received free cyanidinum chloride gel (250 mg/ $\mathrm{kg} / 24 \mathrm{~h})$; group 3 received empty liposomes gel $(250 \mathrm{mg} / \mathrm{kg} /$ $24 \mathrm{~h})$; group 4 received physiological saline gel $(1 \mathrm{~mL} / \mathrm{kg} / 24 \mathrm{~h})$; and group 5, as the positive control group, received amikacin gel $(250 \mathrm{mg} / \mathrm{kg} / 24 \mathrm{~h})$; for 8 days starting from the 3rd day postinfection. Two days after the last dose, the surviving animals were anesthetized and sacrificed by cervical dislocation, and the skin, liver, and spleen of each animal was removed under sterile conditions and homogenized for 5-10 min in PBS ( $2 \mathrm{~mL} / \mathrm{g}$ ). The homogenates were serially diluted and plated for growth in the soybean-casein digest agar medium and incubated at $35^{\circ} \mathrm{C}$ for $24 \mathrm{~h}$, and then the colony forming unit (CFU) was counted. The colony counts were performed in triplicate.

\section{Data analysis}

The results are expressed as means \pm standard errors for all of the experimental measurements. The data from the killing rate study were statistically evaluated by paired Student's t-test, and a p value $<0.05$ was considered significant. The results of the survival rates of the control and treated animals were determined by using the chi-squared test with Yates correction and by Fisher's exact test. 
Table 1 Survival rate of infected mice and colony-forming units (CFUs) of P. aeruginosa ATCC 15692 in different organs.

\begin{tabular}{|c|c|c|c|}
\hline Treatment & Tissue/Organ & Log CFU/Gram tissue & Percentage of survival mice $(n=10)$ \\
\hline $\begin{array}{l}\text { Control without drug administration } \\
\text { (received physiological saline, topically) }\end{array}$ & $\begin{array}{l}\text { Skin } \\
\text { Spleen } \\
\text { Liver }\end{array}$ & $\begin{array}{l}3.213 \pm 0.200 \\
3.871 \pm 0.400 \\
3.182 \pm 0.500\end{array}$ & none survived \\
\hline $\begin{array}{l}\text { Empty liposomes } \\
\left(250 \mathrm{mg} \cdot \mathrm{kg}^{-1} \text {, topically) }\right.\end{array}$ & $\begin{array}{l}\text { Skin } \\
\text { Spleen } \\
\text { Liver }\end{array}$ & $\begin{array}{l}3.316 \pm 0.500 \\
3.766 \pm 1.100 \\
3.210 \pm 0.500\end{array}$ & none survived \\
\hline $\begin{array}{l}\text { Free cyanidinum chloride } \\
\left(250 \mathrm{mg} \cdot \mathrm{kg}^{-1} \text {, topically) }\right.\end{array}$ & $\begin{array}{l}\text { Skin } \\
\text { Spleen } \\
\text { Liver }\end{array}$ & $\begin{array}{l}2.122 \pm 0.300 \\
2.795 \pm 1.100 \\
2.547 \pm 0.120\end{array}$ & 40 \\
\hline $\begin{array}{l}\text { Cyanidinum chloride-loaded liposomes } \\
\left(250 \mathrm{mg} \cdot \mathrm{kg}^{-1} \text {, topically) }\right.\end{array}$ & $\begin{array}{l}\text { Skin } \\
\text { Spleen } \\
\text { Liver }\end{array}$ & $\begin{array}{l}\mathrm{Nil}^{*} \\
0.623 \pm 0.100^{* *} \\
\mathrm{Nil}^{*}\end{array}$ & 100 \\
\hline $\begin{array}{l}\text { Amikacin } \\
\left(250 \mathrm{mg} \cdot \mathrm{kg}^{-1} \text {, topically) }\right.\end{array}$ & $\begin{array}{l}\text { Skin } \\
\text { Spleen } \\
\text { Liver }\end{array}$ & $\begin{array}{l}0.120 \pm 0.200^{* *} \\
0.843 \pm 0.500^{* *} \\
0.355 \pm 0.300^{* *}\end{array}$ & 100 \\
\hline
\end{tabular}

The results are expressed as mean \pm standard error of mean. The analysis of variance of one-way classification between the treatment means was heterogeneous, and the t-test values (two-tailed) were significant. ${ }^{*} \mathrm{p}<0.001$ and ${ }^{* *} \mathrm{p}<0.05$

\section{Supporting information}

The particle size, zeta-potential, and polydispersity index of the empty and cyanidinum chloride-loaded liposomes as well as the size distribution pattern of cyanidinum chloride-loaded liposomes are shown in the Supporting Information.

\section{Results and Discussion}

$\nabla$

The use of plant-derived compounds to eliminate harmful and resistant bacterial infections has been widely investigated $[8,9]$. However, the main problems associated with the application of these materials are insufficient quantities in the target site and in vivo instability [9]. To overcome these problems, the investigators focused on the encapsulation of plant-derived compounds in carriers such as liposomes [29,30]. However, the preparation of plant-derived liposomes with high encapsulation efficacy may not be easy because the variable interactions between these materials and bilayer lipids can occur [31]. In this study, we evaluated the potential of incorporating cyanidinum chloride into liposomes. The results showed that cyanidinum chloride can be encapsulated into the prepared liposomes with high entrapment efficacy $(85.00 \% \pm 0.15)$. It has been shown that positive interaction between lipids and loaded components could enhance entrapment efficacy $[16,17]$, and probably some of the various known types of weak links make the increase of cyanidinum chloride encapsulation efficacy.

The homogeneity of the mean particle size of the empty and loaded liposomes suggested that the cyanidinum chloride was entrapped in the lipid bilayer, according to previous studies [17, 23]. The zeta-potential of the liposomes revealed that the prepared cyanidinum chloride-loaded nanoparticles have appropriate stability in aqueous dispersion [31,32]. The size distribution study showed a monomodal distribution with a mean diameter of $92.5 \pm 0.2 \mathrm{~nm}$.

The MIC values of cyanidinum chloride in both of the free and liposomal forms and amikacin for $P$. aeruginosa ATCC 15692 were $1.5 \times 10^{-3}, 7.7 \times 10^{-4}$, and $6.8 \times 10^{-6} \mathrm{M}$, respectively. The difference between the MICs of the free and liposomal cyanidinum chloride was significant $(\mathrm{p}<0.05)$. Our results suggest that the entrapped cyanidinum chloride in the liposomes enhanced its antibacterial activity against $P$. aeruginosa when compared to the free cyani- dinum chloride. The killing curves of the cyanidinum chloride in the free and encapsulated forms at 1,2, and 4 times the MICs are shown in 1 Fig. 2. In all of the conditions, the encapsulated cyanidinum chloride was more effective on reducing the bacterial counts when compared to the free cyanidinum chloride (- Fig. 2). At one time MIC only, the cyanidinum chloride-loaded liposomes could eliminate $P$. aeruginosa ATCC 15692 after $24 \mathrm{~h}$ ( Fig. 2A). At two times MIC, both the free and encapsulated forms of cyanidinum chloride eradicated the bacteria after 6 and $24 \mathrm{~h}$, respectively ( Fig. 2B). At four times MIC, the cyanidinum chloride-loaded liposomes eliminated the bacteria after $4 \mathrm{~h}$ (० Fig. 2C).

It has been reported that encapsulating methyl-N-methylanthranilate and alcohol $\alpha$-bisabolol (organic compounds from Zanthoxylum tingoassuiba) in liposomes could eliminate the resistant strain of $P$. aeruginosa as well [33]. Some hypotheses, including increasing the penetration of plant-derived materials into bacteria cells and their non-sensitivity to degradation bacterial enzymes, may explain the mechanism of the enhanced antimicrobial activities of these liposomal formulations $[8,33]$. The timekill assays confirmed that the potency of cyanidinum chlorideloaded liposomes was higher than free cyanidinum chloride. As reported previously [20], we hypothesized that the electrostatic interaction between the outer membrane lipopolysaccharides of $P$. aeruginosa and the liposomes could enhance the mechanism of cyanidinum chloride entry into this microorganism's cell. Wounds and other exposed tissues are particularly susceptible to bacterial contamination and infections [34,35]. Compared to the untreated animals, the treatment of the wound-infected mice with cyanidinum chloride-loaded liposomes showed a significant reduction in CFU values in the evaluated organs, especially in the skin and liver ( Table 1). It was found that the mortality of the mice without the administration of cyanidinum chloride was $100 \%$ after 8 days, whereas the animals treated with cyanidinum chloride in free and encapsulated liposomes showed an increase in the survival rate of 40 and $100 \%$, respectively. Also, the viability of the amikacin-treated mice (as positive control) was $100 \%$. It has been proven that the potential mortality from wound infections, even with aggressive antibiotic therapy, may approach or exceed $50 \%$ [36]. The treatment of mice with cyanidinum chloride-loaded liposomes resulted in a $100 \%$ survival rate and in an almost complete eradication of the bacteria from the skin and liv- 
er of each of the infected animals. This data may be due to optimal antibacterial delivery, which has been reported by several investigators [19,37]. It has also been reported that oleic acidloaded liposomes (LipoOA) could eliminate methicillin-resistant Staphylococcus aureus (MRSA) in vitro and in vivo [20]. Also, the encapsulation of usnic acid (a dibenzofuran originally isolated from lichens) improved the burn healing process in rats [19]. When liposomes containing compounds are applied topically, they can interact with the cell membranes of exposed tissues, and therefore protect the wound tissues from further bacterial infections [19,20,37].

In conclusion, the in vitro and in vivo testing showed that cyanidinum chloride-loaded liposomes have a strong protective effect of wounds infected by $P$. aeruginosa ATCC 15692 and may be a good choice for the treatment of patients with such infections.

\section{Acknowledgements}

This study was supported by the Islamic Azad University, Borujerd Branch, Iran. The authors would like to acknowledge staffs of the university.

\section{Conflict of Interest}

The authors report no conflict of interest.

\section{References}

1 Plotnikova JM, Rahme LG, Ausubel FM. Pathogenesis of the human opportunistic pathogen Pseudomonas aeruginosa PA14 in Arabidopsis. Plant Physiol 2000; 124: 1766-1774

2 Buijs J, Dofferhoff AS, Mouton JW, van der Meer JW. Continuous administration of PBP-2- and PBP-3-specific beta-lactams causes higher cytokine responses in murine Pseudomonas aeruginosa and Escherichia coli sepsis. J Antimicrob Chemother 2007; 59: 926-933

3 Gibbons S. Phytochemicals for bacterial resistance-strengths, weaknesses and opportunities. Planta Med 2008; 74: 594-602

4 Kulling SE, Rawel HM. Chokeberry (Aronia melanocarpa) - A review on the characteristic components and potential health effects. Planta Med 2008; 74: 1625-1634

5 Prasad S, Phromnoi K, Yadav VR, Chaturvedi MM, Aggarwal BB. Targeting inflammatory pathways by flavonoids for prevention and treatment of cancer. Planta Med 2010; 76: 1044-1063

6 Truong VD, Hua Z, Thompson RL, Yencho GC, Pecota KV. Pressurized liquid extraction and quantification of anthocyanins in purple-fleshed sweet potato genotypes. J Food Compost Anal 2012; 26: 96-103

7 Truong VD, Deighton N, Thompson RT, McFeeters RF, Dean LO, Pecota KV, Yencho GC. Characterization of anthocyanins and anthocyanidins in purple-fleshed sweetpotatoes by HPLC-DAD/ESI-MS/MS. J Agric Food Chem 2010; 58: 404-410

$8 \mathrm{Naz}$ S, Siddiqi R, Ahmad S, Rasool SA, Sayeed SA. Antibacterial activity directed isolation of compounds from Punica granatum. J Food Sci 2007; 72: 341-345

9 Cushnie TP, Lamb AJ. Antimicrobial activity of flavonoids. Int J Antimicrob Agents 2005; 26: 343-356

10 Hassine DB, Abderrabba M, Yvon Y, Lebrihi A, Mathieu F, Couderc F, Bouajila J. Chemical composition and in vitro evaluation of the antioxidant and antimicrobial activities of Eucalyptus gillii essential oil and extracts. Molecules 2012; 17: 9540-9558

11 Khlifi D, Hamdi M, El Hayouni A, Cazaux S, Souchard JP, Couderc F, Bouajila J. Global chemical composition and antioxidant and anti-tuberculosis activities of various extracts of Globularia alypum L. (Globulariaceae) leaves. Molecules 2011; 16: 10592-10603

12 Safinya CR, Ewert KK, Leal C. Cationic liposome-nucleic acid complexes: liquid crystal phases with applications in gene therapy. Liq Cryst 2011; 38: $1715-1723$

13 Heneweer C, Gendy SE, Peñate-Medina O. Liposomes and inorganic nanoparticles for drug delivery and cancer imaging. Ther Deliv 2012; 3: 645-656

14 Ellbogen MH, Olsen KM, Gentry-Nielsen MJ, Preheim LC. Efficacy of liposome-encapsulated ciprofloxacin compared with ciprofloxacin and ceftriaxone in a rat model of pneumococcal pneumonia. J Antimicrob Chemother 2003; 51: 83-91

15 Zhong Z, Wan Y, Han J, Shi S, Zhang Z, Sun X. Improvement of adenoviral vector-mediated gene transfer to airway epithelia by folate-modified anionic liposomes. Int J Nanomed 2011; 6: 1083-1093

16 Roychoudhury J, Sinha R, Ali N. Therapy with sodium stibogluconate in stearylamine-bearing liposomes confers cure against SSG-resistant Leishmania donovani in BALB/c mice. PLoS One 2011; 6: e17376

17 Fang JY, Hwang TL, Huang YL, Fang CL. Enhancement of the transdermal delivery of catechins by liposomes incorporating anionic surfactants and ethanol. Int J Pharm 2006; 310: 131-138

18 Youfang J, Fenghung C, Longhwang T, Linghuang Y. Physicochemical characteristics and in vivo deposition of liposome-encapsulated tea catechins by topical and intratumor administrations. J Drug Targ 2005; $13: 19-27$

19 Nunes PS, Albuquerque Jr. RL, Cavalcante DR, Dantas MD, Cardoso JC, Bezerra MS, Souza JC, Serafini MR, Quitans Jr. LJ, Bonjardim LR, Araújo AA. Collagen-based films containing liposome-loaded usnic acid as dressing for dermal burn healing. J Biomed Biotechnol 2011; 2011: 761593

20 Huang CM, Chen CH, Pornpattananangkul D, Zhang L, Chan M, Hsieh MF, Zhang L. Eradication of drug resistant Staphylococcus aureus by liposomal oleic acids. Biomaterials 2011; 32: 214-221

21 Committe on the Care and Use of Laboratory Animals of the Institute of Laboratory Animal Resources, Commission on Life Sciences National Research Council. Guide for the care and use of laboratory animals. Washington, D.C.: National Academy Press; 1996

22 Geetha M, Saravanakumar M, Suganya Devi P. HPLC analysis of quercetin and cyanidin from onion peel (Allium cepa L.). Am J Pharm Tech Res 2012; 2: 331-337

23 Gharib A, Faezizadeh Z, Mohammad Asghari H. Preparation and antifungal activity of spray-dried amphotericin B-loaded nanospheres. Daru 2011; 19: 351-355

24 Cabral ECM, Zollner RL, Santana MHA. Preparation and characterization of liposomes entrapping allergenic proteins. Braz J Chem Eng 2004; 21 : 137-146

25 National Committee for Clinical Laboratory Standards. Methods for dilution antimicrobial susceptibility tests for bacteria that grow aerobically: approved standard, 6th edition. Wayne: National Committee for Clinical Laboratory Standards; 2003: NCCLS document M7-A6

26 Shrivastava SM, Saurabh S, Rai D, Dwivedi VK, Chaudhary M. In vitro microbial efficacy of sulbactomax: a novel fixed dose combination of ceftriaxone sulbactam and ceftriaxone alone. Curr Drug Ther 2009; 4: 7377

27 Cao S, Sun LQ Wang M. Antimicrobial activity and mechanism of action of Nu-3, a protonated modified nucleotide. Ann Clin Microbiol Antimicrob 2011; 10: 1-9

28 Mitkari BV, Korde SA, Mahadik KR, Kokare CR. Formulation and evaluation of topical liposomal gel for fluconazole. Indian J Educ Res 2010; 44: 324-333

29 van Vuuren SF, du Toit LC, Parry A, Pillay V, Choonara YE. Encapsulation of essential oils within a polymeric liposomal formulation for enhancement of antimicrobial efficacy. Nat Prod Commun 2010; 5: 1401-1408

30 van Vuuren S, Viljoen A. Plant-based antimicrobial studies-methods and approaches to study the interaction between natural products. Planta Med 2011; 77: 1168-1182

31 Muqbil I, Masood A, Sarkar FH, Mohammad RM, Azmi AS. Progress in nanotechnology based approaches to enhance the potential of chemopreventive agents. Cancers 2011; 3: 428-445

32 Shaffa MW, Dayem SA, Elshemy WM. In vitro antibacterial activity of liposomal cephalexin against Staphylococcus aureus. Romanian J Biophys 2008; 18: 293-300

33 Detoni CB, Cabral-Albuquerque ECM, Hohlemweger SVA, Sampaio C, Barros TF, Velozo EF. Essential oil from Zanthoxylum tingoassuiba loaded into multilamellar liposomes useful as antimicrobial agents. J Microencapsul 2009; 26: 684-691

34 Klein DG, Fritsh DE, Amin SG. Wound infection following trauma and burn injuries. Crit Care Nursing N Am 1995; 7: 627-642

35 Pruitt Jr. BA, McManus AT, Kim SH, Goodwin CW. Burn wound infections: current status. World J Surg 1998; 22: 135-145

36 Wurtz R, Karajovic E, Dacumos E, Hanumandass M. Nosocomial infections in a burn intensive care unit. Burns 1995; 21: 180-184

37 Karodi R, Jadhav M, Rub R, Bafna A. Evaluation of the wound healing activity of a crude extract of Rubia cordifolia L. (Indian madder) in mice. Int J Appl Res Nat Prod 2009; 2: 12-18 